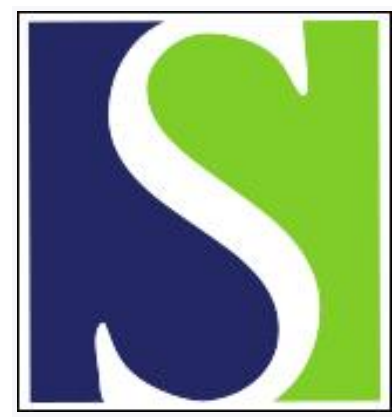

Scand J Work Environ Health 2013;39(4):401-410

https://doi.org/10.5271/sjweh.3344

Published online: 17 Jan 2013, Issue date: 01 Jul 2013

Assessment of the effect of occupational exposure to formaldehyde on the risk of lung cancer in two Canadian population-based case-control studies

by Mahboubi A, Koushik A, Siemiatycki J, Lavoué J, Rousseau M-C

So far, studies on occupational exposure to formaldehyde and lung cancer risk have generated equivocal results. According to the International Agency for Research on Cancer, formaldehyde is a definite carcinogen, specifically for the nasopharynx. We observed no marked increases in lung cancer risk related to workplace formaldehyde exposure, using several metrics of exposure and adjusting the estimates for important confounders.

Affiliation: INRS-Institut Armand-Frappier, 531, boulevard des Prairies, Laval, QC, Canada H7V 1 B7. marie-claude.rousseau@iaf.inrs.ca

Refers to the following text of the Journal: 1990;16(6):394-400

Key terms: Canada; cancer; formaldehyde; lung cancer; lung neoplasm; occupational exposure; population-based study

This article in PubMed: www.ncbi.nlm.nih.gov/pubmed/23329145 


\title{
Assessment of the effect of occupational exposure to formaldehyde on the risk of lung cancer in two Canadian population-based case-control studies
}

\author{
by Amel Mahboubi, PhD, ${ }^{1}$ Anita Koushik, PhD, ${ }^{1,}$ ' Jack Siemiatycki, PhD, ${ }^{1}$ Jérôme Lavoué, PhD, ${ }^{1,3}$ \\ Marie-Claude Rousseau, PhD 1,2,4
}

\begin{abstract}
Mahboubi A, Koushik A, Siemiatycki J, Lavoué J, Rousseau M-C. Assessment of the effect of occupational exposure to formaldehyde on the risk of lung cancer in two Canadian population-based case-control studies. Scand J Work Environ Health. 2013;39(4):401-410. doi:10.5271/sjweh.3344
\end{abstract}

Objective This study aimed to explore the possible association between formaldehyde exposure and lung cancer risk.

Methods Data were collected in two population-based case-control studies conducted in Montreal, Canada. Cases were individuals diagnosed with incident, histologically-confirmed lung cancer. Controls were randomly selected from electoral lists and frequency-matched to cases by age, sex, and electoral district of residence. Interviews for the two studies were conducted in 1979-1986 and 1996-2002, using a virtually identical questionnaire to obtain lifetime occupational and smoking history and several lifestyle covariates. Experts reviewed the detailed work history for each participant to assess exposure to several occupational agents, including formaldehyde. Logistic regression was used to estimate odds ratios (OR) and 95\% confidence intervals (95\% CI) for the associations between several metrics of formaldehyde exposure and lung cancer, adjusting for smoking and occupational and sociodemographic factors.

Results In all, 2060 lung cancer cases and 2046 population controls were interviewed and assessed for exposure. About $25 \%$ of subjects had ever been occupationally exposed to formaldehyde. The adjusted OR for lung cancer was 1.06 (95\% CI 0.89-1.27) comparing ever versus never exposure to formaldehyde. Analyses for age at first exposure, average, and peak intensity of exposure also suggested an absence of association between formaldehyde exposure and lung cancer risk. Results did not vary by sex, lifetime smoking intensity, or histological subtype.

Conclusions No marked increases in lung cancer risk related to workplace formaldehyde exposure were observed. Study participants were mainly exposed at low concentration levels, which should be considered in the interpretation of our findings.

Key terms Canada; lung neoplasm.

Formaldehyde $\left(\mathrm{CH}_{2} \mathrm{O}\right)$ is an organic compound widely used throughout the world, particularly in the production of resins used in the wood (pressed wood products), paper (paper product coatings), and textile (permanent press fabrics) industries. It is also found in varnishes, glues, and plastics. As formalin, it is also utilized as a disinfectant and tissue preservative for medical purposes (1).

Given its association with nasopharyngeal cancer (2), formaldehyde has recently been classified as carcinogenic to humans (Group 1) (3). Because of its polar- ized aldehyde $(\mathrm{H}-\mathrm{C}=\mathrm{O})$ group, formaldehyde reacts quickly when it comes in contact with the body. Thus, it is plausible that exposure can lead to cancer at the first body site encountered by this chemical, such as the nasopharynx. However, formaldehyde could also induce cancer in the lower part of the respiratory tract as it has been shown previously that inhaled formaldehyde reaches the lungs (4).

Although cigarette smoking is the primary risk factor for lung cancer, nearly all other known lung carcinogens

1 University of Montreal Hospital Research Center (CRCHUM), Montreal, QC, Canada.

2 Department of Social and Preventive Medicine, University of Montreal, Montreal, QC, Canada.

3 Department of Environmental and Occupational Health, University of Montreal, Montreal, QC, Canada.

4 INRS-Institut Armand-Frappier, Laval, QC, Canada.

Correspondence to: Marie-Claude Rousseau, INRS-Institut Armand-Frappier, 531, boulevard des Prairies, Laval, QC, Canada H7V 1B7. [E-mail: marie-claude.rousseau@iaf.inrs.ca] 
(eg, asbestos and silica) are occupational exposures (5). The Report on Carcinogens Background Document for Formaldehyde from the US National Toxicology Program (1) considered 23 studies that reported on the association between exposure to formaldehyde and lung cancer risk (2, 6-28). Overall, these studies generated equivocal results, with small increases in risk observed in some studies $(6,9-13,22-24,27)$, though reaching statistical significance only in four $(10,11,24,27)$. A wide variety of exposure assessment methods and combinations thereof were used to assess individual exposure to formaldehyde. Some of the older studies used job title (often embalmers or pathologists) as a proxy for exposure $(8,14-17,19,21)$ or a more elaborate job exposure matrix (JEM) but focused on the last job held as indicated on the death certificate (27). Other methods included the use of (i) employment records $(2,6,7,9$, $10,12,13,18,22,25,26$ ), (ii) a JEM, (iii) industrial hygiene data $(2,6,10,18,22,23,25,26)$, or (iv) selfreport of exposure to formaldehyde $(11,20,24)$ or occupational history $(23,28)$. Information on smoking, a key potential confounder, was available and accounted for in the analyses in only seven studies $(6,11,20,22,24$, $25,28)$, some of which had large proportions of missing values for smoking variables. Similarly, few studies had information on exposure to other occupational lung carcinogens that may be correlated with formaldehyde exposure $(2,6,11,22,28)$. In addition, only six studies $(2,13,16,20,21,29)$ included women in their study population, though analyses by gender were reported in only three studies $(13,16,20)$.

We examined the association between occupational exposure to formaldehyde and lung cancer risk among men and women in two population-based case-control studies carried out in Montreal, Canada. These studies included detailed occupational history and extensive information on various personal, lifestyle, and environmental factors. Study I was conducted in 1979-1986 and designed to investigate many types of cancer among men, while Study II (1996-2002) focused on lung cancer among men and women. Selected results on formaldehyde exposure and lung cancer from Study I were published in an earlier article (28). The present report is not only based on pooled data from both studies but also relies on updated exposure assessments and improved statistical methods.

\section{Methods}

\section{Study population}

The study population included participants from two case-control studies conducted in Montreal in the prov- ince of Quebec, Canada. Both studies used the same methodology, which has previously been described in detail (30-32).

Briefly, cases were Canadian citizens residing in the Montreal metropolitan area during the study period, and diagnosed with an incident, histologically confirmed cancer at one of the 18 Montreal-area hospitals. Study I included males aged 35-70 years and diagnosed with one of $>20$ types of tumors, including lung cancer, while Study II included both males and females aged 35-75 years diagnosed with lung cancer. Overall, 1082 and 1424 lung cancer cases were identified in Studies I and II, respectively. Ethical approval was obtained from all participating hospitals and universities, and all participants provided informed consent.

Population controls were identified from the Quebec electoral list. Men and women residing in Montreal were randomly sampled and matched to the distribution of sex and age among cases. In the province of Quebec, electoral lists are based on active procedures to enroll eligible voters, including household enumeration and record linkage with various government databases. It is estimated that $92 \%$ of truly eligible citizens residing in the province are on the list (33). There were 740 and 2179 eligible controls identified in Studies I and II, respectively.

Among the eligible individuals identified, 857 cases and 533 controls agreed to participate (response rates of $79 \%$ and $72 \%$, respectively) in Study I, and 1203 cases and 1513 controls agreed to participate (response rates of $84 \%$ and $69 \%$, respectively) in Study II, for a total study population of 2060 cases and 2046 controls.

\section{Data collection}

Participants or a next-of-kin were interviewed for data collection. Proxy respondents provided information for $29.4 \%$ of cases and $12.6 \%$ of controls in Study I and $37.7 \%$ of cases and $7.8 \%$ of controls in Study II. Interviews were divided into two sections: a structured questionnaire focusing on sociodemographic characteristics (eg, age, ethnocultural origin, family income, and education) as well as lifestyle habits (eg, smoking, alcohol consumption) and a semi-structured questionnaire to obtain a complete work history. For each job held by the subject, a trained interviewer asked about the company, its products, the nature of the worksite, the subject's main and subsidiary tasks, and any additional information (eg, equipment maintenance, use of protective equipment, activities of coworkers) that may be pertinent regarding work exposures and their intensity. For some occupations, supplementary questionnaires were used to assist the interviewers with detailed technical probing (34). 


\section{Occupational exposure assessment}

The exposure assessment method has been described elsewhere $(30,32,35)$. Briefly, occupations were coded according to the 1971 Canadian Classification and Dictionary of Occupations (36). A team of trained chemists and industrial hygienists reviewed each participant's work history and then translated each job into a list of potential exposures without knowledge of the case or control status. They based their assessment on a checklist of 294 agents of interest, which included formaldehyde. Using their collective judgment and knowledge of industry, the team of experts took into account the specific tasks reported by study subjects and their description of the workplace rather than simply attributing exposure based on job title and industry.

For each agent considered present for a particular job, the chemists/industrial hygienists classified exposure according to three dimensions: (i) their degree of confidence that the exposure had actually occurred (possible, probable, and definite), (ii) the relative concentration of the agent (low, medium, and high), and (iii) the frequency of exposure in a normal work week. The relative concentration of each agent was established with reference to benchmark occupations in which workers are exposed to the agent, some of which were well documented with industrial hygiene measurements from the literature and others were based on the experts' accumulated knowledge. For each agent, subjects exposed up to the level found in the general environment were considered as unexposed. The frequency parameter was coded directly as a percentage in Study II but was categorical in Study I (low: $<5 \%$, medium 5-30\%, high $>30 \%$ of the work week). Since a quantitative value of frequency was needed for the calculation of the cumulative exposure index (see below), we estimated a quantitative value for each frequency category in Study I using frequency information from Study II. Specifically, in Study II we identified all formaldehyde-exposed jobs that overlapped for at least one year with the common temporal window of occupational history between the two studies (1950-1980). Among these jobs in Study II, and in the three subgroups defined by the same frequency cutoff points as in Study I, we determined the mean and median frequency of exposure to formaldehyde. We then assigned the midpoint between the mean and median to each category in Study I. Low frequency was assigned as occurring over $2.6 \%$, medium over $14.2 \%$, and high frequency over $98.9 \%$ of the work week, respectively.

\section{Variable definitions}

An index of exposure to formaldehyde was created to summarize cumulative exposure on a continuous scale for each individual. Only probable and definite expo- sures to formaldehyde occurring $\geq 5$ years before recruitment were considered. The index was calculated as the sum, over all jobs, of the following product:

Concentration level $\times$ frequency of exposure ( $\%$ of time exposed in job) $\times$ number of years exposed in job

Numerical values of 1,3 , and 9 were assigned to low, intermediate, and high concentration levels, respectively. These weights represent the opinions of our expert coders as to how they used these categories (eg, that concentrations coded as intermediate were generally 3 -fold greater than those coded as low). Among ever-exposed cases and controls from both studies combined, those who were in the top $25^{\text {th }}$ percentile of the index were considered as exposed at a substantial level, while the others were considered exposed at a non-substantial level.

We also examined other metrics of exposure to formaldehyde, including age at first exposure ( $\leq 20$ years, $>20-29$ years, $>29$ years), duration of exposure ( $\leq 6$ years, $>6-20$ years, $>20$ years), time elapsed since first exposure ( $\leq 32$ years, $>32-43$ years, $>43$ years), and maximum concentration of formaldehyde encountered (low, intermediate, high). The category cut-off points for variables with continuous values were determined according to tertiles based on the distribution among controls.

\section{Data analysis}

Odds ratios (OR) and 95 percent confidence intervals $(95 \% \mathrm{CI})$ were estimated using unconditional logistic regression in order to approximate the relative risk of lung cancer associated with each of the exposure metrics (37). Several potential confounders were taken into account, including age $(<55,55-64,>65$ years $)$, sex, census-based family income of the neighborhood of residence (low, medium, high), ethnocultural origin (French ancestry, English ancestry, other), respondent status (self, proxy) and number of years of schooling $(<7,7-12, \geq 13$ years). Tobacco smoking was taken into account using the comprehensive smoking index (CSI), a continuous variable that incorporates information on smoking status, duration of smoking, amount smoked, as well as time since quitting in the case of former smokers (38). Analyses were also adjusted for recognized occupational lung carcinogens (39) with a prevalence of $>2 \%$ in the study population, namely, asbestos and silica. Exposure to each of these carcinogens was taken into account using a categorical variable (ever/never exposed), where ever exposed indicates that the participant had $\geq 1$ job with a rating of at least possible exposure to a low level of the specific carcinogen.

Analyses were first conducted on the whole study population, as well as in strata defined by sex and smoking status ("never/light smokers" versus "medium/heavy 
smokers"). Smokers who belonged to the $1^{\text {st }}$ quartile of the distribution of the continuous covariate CSI were regrouped with individuals who had never smoked to form the "never/light smokers" group. Smokers who belonged to the $2^{\text {nd }}-4^{\text {th }}$ quartiles of the distribution of the continuous covariate CSI formed the "medium/heavy smokers" group. In addition, separate analyses were conducted to examine the effects of occupational exposure to formaldehyde on each of the main histologic types of lung cancer (adenocarcinoma, small cell carcinoma, and squamous cell carcinoma). All analyses were carried out using the R software (40) and the Epicalc library (41).

\section{Results}

Table 1 shows the distribution of our study population according to selected characteristics. As expected by the design of both studies, cases and controls were well balanced according to age and, in Study II, also according to sex. Overall, controls had higher levels of education and family income than cases. A majority of participants, and a slightly higher proportion among cases than controls, were of French ancestry. As expected, smoking was much more prevalent among cases than controls. Among male lung cancer cases from both studies, squamous cell carcinoma was the most common histological subtype (41.9\% Study I; 35\% Study II), followed by adenocarcinoma (19.5\% Study I; 32.6\% Study II). Among female lung cancer cases, almost half were adenocarcinoma (46.7\%); the remaining cases were almost equally divided between other histological subtypes.

Table 1 also shows the distribution of exposure to formaldehyde according to various exposure metrics. Among the 4106 individuals, 1023 (24.9\%) were ever exposed to formaldehyde. Lifetime prevalence of exposure among males was similar between cases and controls: $20.8 \%$ for cases and $19.3 \%$ for controls in Study I and $22.9 \%$ for cases and $24.7 \%$ for controls in Study II. Lifetime prevalence of formaldehyde exposure was higher among females than males and higher among female cases than controls: $35.5 \%$ of female cases and $30.3 \%$ of female controls were ever exposed, the differences occurring mainly at non-substantial levels. Among men, patterns of exposure based on the cumulative index were similar in Studies I and II. Duration and age at first exposure were relatively similar between cases and controls, except among women for whom exposure lasted fewer years and occurred earlier among cases than among controls. Compared to Study I, a long time had elapsed since first exposure ( $>43$ years) among a greater proportion of cases and controls in Study II. Among both cases and controls, maximum concentration was lower in Study II than Study I.
Table 1. Selected characteristics of the study population in two case-control studies, Montreal (Canada).

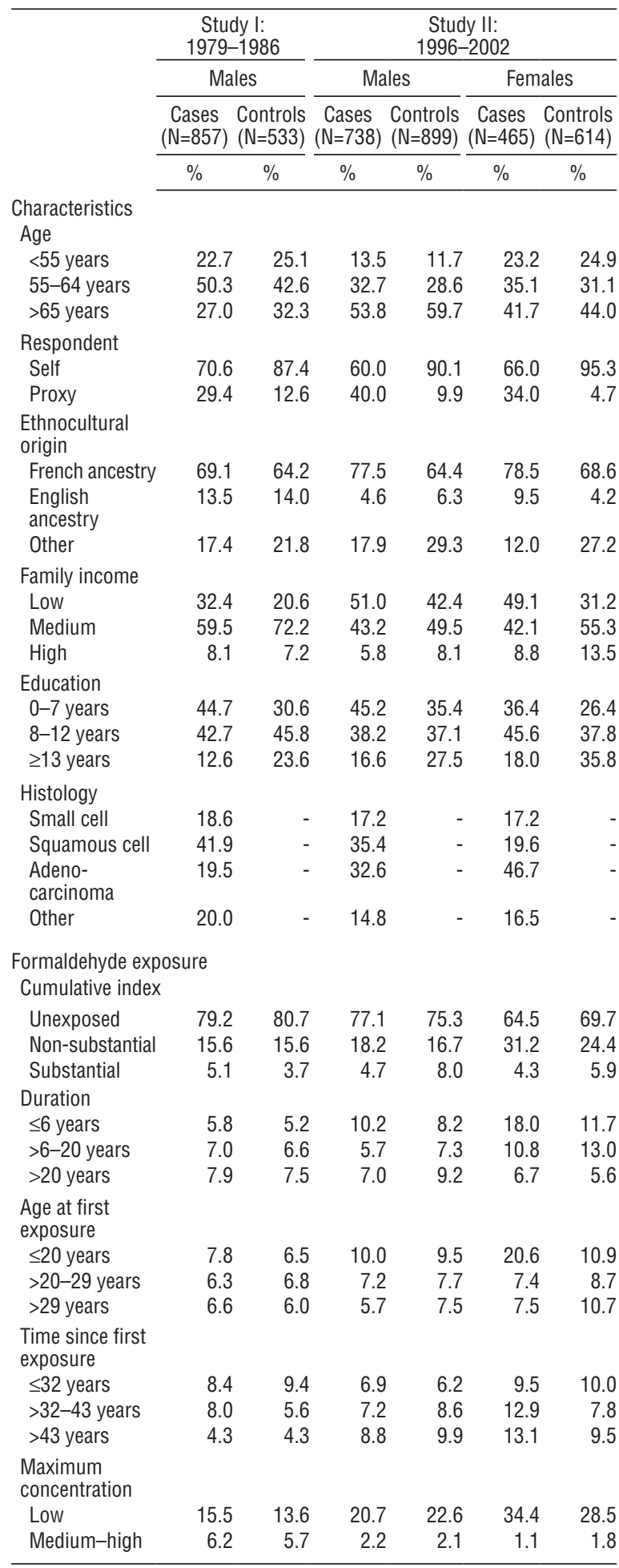


Table 2 presents the main occupations for which the experts attributed exposure to formaldehyde in our study population. Occupations in the food and beverage industry were predominant among both males and females (chefs and cooks; food and beverage serving occupations; supervisors, food and beverage preparation and related service occupations). These occupations were assigned exposure in relation to fumes emitted during deep frying. Our experts frequently attributed formaldehyde exposure to carpenters and related occupations, based on the use of glues and processing of reconstituted wood products. Occupations in the textile industry represented a significant proportion of the exposed jobs in our study (over $30 \%$ of the occupations to which formaldehyde exposure was attributed among females), exposure being due to formaldehyde-containing resins used to confer crease resistance to fabrics. In Study II, farm workers (fumigation, formaldehyde-releasing fertilizers) and firefighters (combustion fumes) were also among the most frequently exposed occupations. In addition to carpenters, occupations in the food and beverage and the textile industries were overwhelmingly associated with low exposure, whereas medium exposure was often attributed to occupations in farming, cabinet and wood furniture makers, and firefighters. Processes and tasks traditionally associated with high formaldehyde exposure (eg, foundry, embalming, pathology) do not appear in table 2 , because very few subjects held related occupations.

Crude and adjusted OR for the association between formaldehyde exposure and lung cancer risk are presented in table 3. When comparing individuals ever exposed to those never exposed, we observed OR $1.06(95 \% \mathrm{CI}$ 0.86-1.31) for men, OR $1.02(95 \%$ CI $0.71-1.47)$ for women, and OR 1.06 (95\% CI 0.89-1.27) for men and women combined. Similarly, when considering the level of cumulative exposure to formaldehyde, categorized as substantial or non-substantial and as compared to individuals never exposed, we observed no evidence of association with lung cancer overall, among men or women. Associations for men did not significantly differ when comparing Study I and Study II. Adjusted OR were 1.20 (95\% CI 0.64-2.24) in Study I and 0.76 (95\% CI $0.45-1.26$ ) in Study II among men for substantial exposure versus never exposed. For non-substantial exposure versus never exposed, adjusted OR were $0.96(0.68-1.36)$ in Study I and $1.28(0.93-1.76)$ in Study II among men $(\mathrm{P}$-value for test for interaction by study $=0.17)$.

There was a slight suggestion of an increased lung cancer risk among those exposed to formaldehyde for short durations, which was statistically significant when pooling all study subjects. Among females, younger age at first exposure was associated with a non-significant increased risk. No association overall was observed with time since first exposure or maximum concentration of exposure. There was a suggestion of increasing lung cancer risk with increasing maximum formaldehyde concentration among males, but again not statistically significant. In each of the analyses presented in table 3 , there was no evidence of modification of OR by $\operatorname{sex}(\mathrm{P}>0.26$ for all tests of interaction by sex). Thus, subsequent analyses were conducted on the pooled population.

Table 2. Characteristics of the main occupational groups to which exposure to formaldehyde was attributed, according to sex and study.

\begin{tabular}{|c|c|c|c|c|c|}
\hline Occupational groups & N & $\begin{array}{l}\text { Percent- } \\
\text { age } 1^{\text {a }}\end{array}$ & $\begin{array}{l}\text { Percent- } \\
\text { age } 2^{\mathrm{b}}\end{array}$ & $\begin{array}{l}\text { Most frequent } \\
\text { exposure } \\
\text { intensity } \\
\end{array}$ & $\begin{array}{c}\text { Median frequency } \\
\text { of exposure } \\
\text { (\% of work week) }\end{array}$ \\
\hline Exposed jobs for males in Study I (1979-1986) & 1424 & & & & \\
\hline Carpenters and related occupations & 99 & 6.9 & 41.3 & Low & 20.0 \\
\hline Chefs and cooks & 90 & 6.4 & 52.3 & Low & 60.0 \\
\hline General workers, farm & 65 & 4.6 & 20.2 & Medium & 5.0 \\
\hline Supervisors, food and beverage preparation, and related service occupations & 47 & 3.3 & 38.5 & Low & 60.0 \\
\hline Cabinet and wood-furniture makers & 41 & 2.8 & 87.2 & Medium & 20.0 \\
\hline Exposed jobs for males in Study II (1996-2002) & 635 & & & & \\
\hline Chefs and cooks & 77 & 12.1 & 90.6 & Low & 100.0 \\
\hline Food and beverage serving occupations & 33 & 5.2 & 38.4 & Low & 18.8 \\
\hline Carpenters and related occupations & 32 & 5.0 & 29.6 & Low & 22.5 \\
\hline Tailors and dressmakers & 31 & 4.9 & 81.6 & Low & 100.0 \\
\hline Patternmaking, marking and cutting occupations: textile, fur and leather products & 30 & 4.7 & 76.9 & Low & 100.0 \\
\hline Exposed jobs for females in Study II (1996-2002) & 609 & & & & \\
\hline Sewing machine operators, textile and similar materials & 162 & 26.6 & 74.0 & Low & 100.0 \\
\hline Food and beverage serving occupations & 130 & 21.4 & 66.0 & Low & 14.5 \\
\hline Sales workers, commodities & 35 & 5.8 & 43.2 & Low & 80.0 \\
\hline Chefs and cooks & 27 & 4.4 & 47.4 & Low & 37.5 \\
\hline Fabricating, assembling, and repairing occupations: textile, fur and leather products & 26 & 4.3 & 66.7 & Low & 100.0 \\
\hline
\end{tabular}


Table 3. Odds ratios (OR) for the associations between occupational exposure to formaldehyde and lung cancer, according to sex and in the whole study population. [ $95 \% \mathrm{Cl}=95 \%$ confidence interval; $0 \mathrm{R}_{\text {adj }}=$ adjusted $\mathrm{OR} ; \mathrm{OR}_{\text {crude }}=$ crude $\mathrm{OR}$ ]

\begin{tabular}{|c|c|c|c|c|c|c|c|c|c|c|c|c|}
\hline \multirow[t]{2}{*}{ Exposure metric } & \multicolumn{4}{|c|}{ Males } & \multicolumn{4}{|c|}{ Females } & \multicolumn{4}{|c|}{ Population pooled } \\
\hline & $\begin{array}{l}\text { Cases/ } \\
\text { Controls }\end{array}$ & $O \mathrm{R}_{\text {crude }}{ }^{\mathrm{a}}$ & $\mathrm{OR}_{\mathrm{adj}} \mathrm{b}$ & $95 \% \mathrm{Cl}$ & $\begin{array}{l}\text { Cases/ } \\
\text { Controls }\end{array}$ & $\mathrm{OR}_{\text {crude }}$ & $O \mathrm{R}_{\mathrm{adj}} \mathrm{b}$ & $95 \% \mathrm{Cl}$ & $\begin{array}{l}\text { Cases/ } \\
\text { Controls }\end{array}$ & $O \mathrm{R}_{\text {crude }}{ }^{\mathrm{a}}$ & $O \mathrm{R}_{\mathrm{adj}} \mathrm{b}$ & $95 \% \mathrm{Cl}$ \\
\hline \multicolumn{13}{|c|}{ Formaldehyde exposure } \\
\hline Never exposed & $1248 / 1107$ & 1.00 & 1.00 & & $300 / 428$ & 1.00 & 1.00 & & $1548 / 1535$ & 1.00 & 1.00 & \\
\hline Ever exposed & $347 / 325$ & 0.98 & 1.06 & $0.86-1.31$ & $165 / 186$ & 1.27 & 1.02 & $0.71-1.47$ & $512 / 511$ & 1.06 & 1.06 & $0.89-1.27$ \\
\hline Non-substantial & $268 / 233$ & 1.05 & 1.12 & $0.89-1.42$ & $145 / 150$ & 1.38 & 1.08 & $0.73-1.58$ & $413 / 383$ & 1.15 & 1.12 & $0.92-1.37$ \\
\hline Substantial & $79 / 92$ & 0.81 & 0.90 & $0.62-1.32$ & $20 / 36$ & 0.79 & 0.73 & $0.32-1.64$ & $99 / 128$ & 0.80 & 0.88 & $0.63-1.24$ \\
\hline \multicolumn{13}{|c|}{ Duration of exposure } \\
\hline & $125 / 101$ & 1.20 & 1.31 & $0.94-1.82$ & $84 / 72$ & 1.66 & 1.36 & $0.84-2.20$ & 209/173 & 1.36 & 1.36 & $1.04-1.78$ \\
\hline$>6-20$ & $102 / 101$ & 0.89 & 1.05 & $0.74-1.50$ & $50 / 80$ & 0.89 & 0.65 & $0.38-1.12$ & $152 / 181$ & 0.88 & 0.90 & $0.67-1.20$ \\
\hline$>20$ & $120 / 123$ & 0.88 & 0.89 & $0.65-1.22$ & $31 / 34$ & 1.30 & 1.18 & $0.55-2.54$ & $151 / 157$ & 0.96 & 0.93 & $0.69-1.24$ \\
\hline \multicolumn{13}{|l|}{ Age at first exposure } \\
\hline$\leq 20$ & $141 / 120$ & 1.10 & 1.10 & $0.80-1.50$ & $96 / 67$ & 2.04 & 1.44 & $0.90-2.31$ & $237 / 187$ & 1.39 & 1.21 & $0.93-1.56$ \\
\hline$>20-29$ & $107 / 105$ & 0.93 & 1.09 & $0.78-1.53$ & $34 / 53$ & 0.92 & 0.86 & $0.45-1.64$ & $141 / 158$ & 0.92 & 1.05 & $0.78-1.41$ \\
\hline$>29$ & $99 / 100$ & 0.89 & 0.99 & $0.70-1.41$ & $35 / 66$ & 0.76 & 0.59 & $0.31-1.12$ & $134 / 166$ & 0.84 & 0.89 & $0.66-1.21$ \\
\hline \multicolumn{13}{|c|}{ Time since first exposure } \\
\hline$\leq 32$ & $123 / 106$ & 0.99 & 1.09 & $0.79-1.52$ & $44 / 80$ & 0.78 & 0.69 & $0.39-1.21$ & $167 / 186$ & 0.90 & 0.98 & $0.74-1.29$ \\
\hline$>32-43$ & $122 / 107$ & 1.04 & 1.07 & $0.77-1.49$ & $60 / 48$ & 1.78 & 1.51 & $0.85-2.68$ & $182 / 155$ & 1.23 & 1.18 & $0.89-1.56$ \\
\hline$>43$ & $102 / 112$ & 0.91 & 1.02 & $0.72-1.45$ & $61 / 58$ & 1.50 & 1.07 & $0.61-1.90$ & $163 / 170$ & 1.08 & 1.05 & $0.78-1.41$ \\
\hline \multicolumn{13}{|c|}{ Maximum concentration } \\
\hline Low & $277 / 275$ & 0.96 & 1.01 & $0.80-1.27$ & $160 / 175$ & 1.30 & 1.08 & $0.74-1.57$ & $437 / 450$ & 1.07 & 1.04 & $0.86-1.26$ \\
\hline Medium-high & $70 / 50$ & 1.06 & 1.34 & $0.86-2.09$ & $5 / 11$ & 0.65 & 0.40 & $0.11-1.42$ & $75 / 61$ & 1.01 & 1.22 & $0.80-1.84$ \\
\hline
\end{tabular}

a Adjusted for study.

${ }^{b}$ Adjusted for study [for males and population pooled], age, sex [for population pooled], ethnocultural origin (French ancestry, English ancestry or other), family income level (low, medium, or high), proxy respondent (yes or no), smoking (comprehensive smoking index), occupational exposure to asbestos and to silica [for males and population pooled].

Table 4. Odds ratios $(\mathrm{OR})$ for the associations between occupational exposure to formaldehyde and lung cancer, according to lifetime smoking intensity. [95\% $\mathrm{Cl}=95 \%$ confidence interval]

\begin{tabular}{|c|c|c|c|c|c|c|}
\hline \multirow{2}{*}{$\begin{array}{l}\text { Formaldehyde } \\
\text { exposure }\end{array}$} & \multicolumn{3}{|c|}{ Never/light smokers a } & \multicolumn{3}{|c|}{ Medium/heavy smokers } \\
\hline & Cases/Controls & $\mathrm{OR}_{\mathrm{adj}}^{\mathrm{b}}$ & $95 \% \mathrm{Cl}$ & Cases/Controls & $\mathrm{OR}_{\mathrm{adj}} \mathrm{b}$ & $95 \% \mathrm{Cl}$ \\
\hline Unexposed & $251 / 876$ & 1.00 & & $1270 / 650$ & 1.00 & \\
\hline Non-substantial & $49 / 230$ & 0.88 & $0.60-1.30$ & $361 / 150$ & 1.22 & $0.96-1.54$ \\
\hline Substantial & $15 / 70$ & 0.96 & $0.50-1.87$ & $83 / 58$ & 0.84 & $0.57-1.26$ \\
\hline
\end{tabular}

a Individuals who have never smoked and individuals who belonged to the 1st quartile of the distribution of the continuous covariate comprehensive smoking index were considered to form the "never/light smokers" group.

${ }^{b}$ Adjusted for study, age, sex, ethnocultural origin (French ancestry, English ancestry, or other), family income level (low, medium, or high), proxy respondent (yes or no), smoking (comprehensive smoking index), occupational exposure to asbestos and to silica.

Table 4 shows the adjusted OR for formaldehyde, stratified by smoking status. Formaldehyde exposure was not associated with lung cancer risk among never/ light smokers or medium/heavy smokers. We also observed no associations between formaldehyde and different histological types of lung cancer (table 5).

\section{Discussion}

Using data pooled from two large, population-based case-control studies, we observed that formaldehyde exposure was not associated with lung cancer risk overall. The associations did not appreciably differ among subgroups defined by sex and smoking level or according to lung cancer histology. This was generally consistent across different metrics of formaldehyde exposure.

Ever exposure to formaldehyde in relation to lung cancer risk has been examined in 23 studies and reviewed in 2010 by the US National Toxicology Program (1). Findings from these studies did not strongly support an effect of formaldehyde on lung cancer risk. Statistically significant positive associations were observed in only 2 of the 14 cohort studies $(2,6-19)$ : in the subgroup of wood-related workers from a general US population cohort (11) and a large occupational cohort of British workers (10). For three cohorts, results showed positive associations although not statistically 
Table 5. Odds ratios (OR) for the associations between occupational exposure to formaldehyde and lung cancer by histological subtypes. $[95 \% \mathrm{Cl}=95 \%$ confidence interval]

\begin{tabular}{|c|c|c|c|c|c|c|c|c|c|}
\hline \multirow{2}{*}{$\begin{array}{l}\text { Formaldehyde } \\
\text { exposure }\end{array}$} & \multicolumn{3}{|c|}{ Squamous cell carcinoma } & \multicolumn{3}{|c|}{ Small cell carcinoma } & \multicolumn{3}{|c|}{ Adenocarcinoma } \\
\hline & Cases/Controls & $\mathrm{OR}_{\mathrm{adj}}^{\mathrm{a}}$ & $95 \% \mathrm{Cl}$ & Cases/Controls & $\mathrm{OR}_{\mathrm{adj}}^{\mathrm{a}}$ & $95 \% \mathrm{Cl}$ & Cases/Controls & $\mathrm{OR}_{\mathrm{adj}}^{\mathrm{a}}$ & $95 \% \mathrm{Cl}$ \\
\hline Unexposed & $541 / 1535$ & 1 & & $272 / 1535$ & 1 & & $464 / 1535$ & 1 & \\
\hline Non-substantial & $137 / 383$ & 1.18 & $0.90-1.54$ & $79 / 383$ & 1.22 & $0.86-1.74$ & $128 / 383$ & 1.09 & $0.83-1.42$ \\
\hline Substantial & $33 / 128$ & 0.82 & $0.51-1.32$ & $15 / 128$ & 0.82 & $0.41-1.62$ & $33 / 128$ & 1.06 & $0.67-1.68$ \\
\hline
\end{tabular}

significant $(6,9)$, one among women only (13). In two smaller cohorts of health professionals, statistically significant inverse associations (standardized mortality ratios) were reported $(8,16)$. Both studies included few exposed cases and used information from professional associations to assign formaldehyde exposure according to health profession. Among the nine case-control studies (20-28), statistically significant positive associations were reported in only two: a UK population-based study (27) and a more recent hospital-based case-control study conducted in Uruguay (24). Both were among the case-control investigations with the largest numbers of exposed cases.

Among the same 23 studies, only a few further analyzed each of the more refined measures of formaldehyde exposure, including exposure level $(2,10,12,27)$, lifetime cumulative exposure $(2,6,23,28)$, duration of exposure $(2,6,7,9,10,18,24)$, time since first exposure $(6,7,18)$, and peak exposure (2). However, even when formaldehyde exposure was analyzed using these more detailed metrics, increased risks were observed only in two studies with high exposure level (10) and longer exposure duration (24), and a decreased risk was reported with longer duration in another (7). More recently, Checkoway and collaborators (42) reported an increased risk of lung cancer among female textile workers exposed to formaldehyde for $>10$ years, although not statistically significant and based on small numbers (42).

We examined various metrics of formaldehyde exposure and, consistent with the majority of previous studies, did not observe an association between formaldehyde exposure and lung cancer risk overall. The fact that an association was also not observed among subgroups defined by sex, smoking level, or histological subtype further supports formaldehyde not being associated with lung cancer risk. Our null results among women are consistent with those reported in the only three studies presenting results separately for women $(13,16,20)$, among which there was no evidence of an association. To our knowledge, our female case series represents the largest used to study formaldehyde to date and the one with the greatest proportion of exposed women (35.5\%). Lastly, on stratifying by cumulative smoking history, our results were concordant with those from two studies in which subgroups defined by smoking status were examined $(6,23)$ where differences in the formaldehyde-lung cancer associations were not apparent.

Despite the overall lack of a convincing association between formaldehyde and lung cancer in epidemiological studies, an in vitro model that mimics in vivo exposure of human lung cells to gases has recently shown that formaldehyde modified the microRNA patterns involved in gene expression regulation, specifically for genes involved in pathways related to inflammation and cancer (43). There are some biological and methodological reasons that could explain the absence of association in our study and others. Only a small fraction of inhaled formaldehyde actually reaches the lungs (4), thus it may be that an effect of formaldehyde is observable at the population level only at a certain average, maximum concentration, or duration of exposure. In our study, even those exposed at a substantial level over their lifetime did not experience higher lung cancer risk. Non-differential misclassification of exposure to formaldehyde could have brought about the null results that we observed, but they may also reflect that there is no true association.

Some limitations should be considered when interpreting our results. Exposure to formaldehyde was not measured quantitatively. Rather, it was based on semi-quantitative exposure information determined by experts from a review of the detailed lifetime occupational history. This approach has been shown to have good reliability (44-46) and validity (47). Nonetheless, misclassification of exposure to formaldehyde cannot be ruled out. However, since the occupational coding was conducted without knowledge of disease status, misclassification would be non-differential and would have therefore masked a true association. Another potential limitation is that a large proportion of subjects exposed to formaldehyde worked as cooks, other food-related occupations, and in textile-related occupations. In these jobs, a large proportion of workers are exposed to formaldehyde but at a low concentration level, which may not have been high enough to observe an effect. For some subjects, occupational history was provided by a proxy, which could have resulted in misclassification of formaldehyde exposure. However, these errors 
would be minimized by the fact that a majority of proxy respondents were spouses who had knowledge of their spouses' job history, from which our experts attributed exposure to formaldehyde. When we performed sensitivity analyses restricted to self-respondents, results were unchanged (data not shown).

A major strength of our study is the large study population that included 2060 biopsy-confirmed lung cancer cases, thereby representing the largest case series published to date. Unlike most previous studies that were based on occupational cohorts $(2,6-10,12-19,22,23$, 25,26 ), our case-control study was population-based and thus evaluated a wide range of levels of exposure to formaldehyde, as well as considered the entire occupational history. The lifetime prevalence of exposure to formaldehyde was high, $25.0 \%$ among all controls and $24.9 \%$ among all cases, leading to relatively large numbers of exposed subjects. Participation rates were relatively high in both studies I and II, thereby reducing the potential for selection bias (48). Furthermore, we presented results separately for women, stratified our analyses according to smoking levels, and estimated the associations according to histological subtypes, thus providing results for subgroups not often analyzed in previous studies. Finally, an important strength of our study is that it took into account many important potential confounders such as age, ethnocultural origin, income, education, and the main lung carcinogens, ie, smoking using the CSI and occupational lung carcinogens (asbestos and silica).

In summary, we conducted comprehensive analyses using several metrics of exposure, studying specific subgroups of the population and adjusting the estimates for important confounders. However, individuals were often exposed at low concentration levels, which should be considered in the interpretation of our findings. Overall, our results do not support an increased risk of lung cancer among workers exposed to formaldehyde, in line with most previous studies.

\section{Acknowledgments}

Lesley Richardson contributed to the design of the studies and developed and coordinated the data collection methods. Marie-Elise Parent participated in the supervision of data collection and data management. Michel Gérin, Louise Nadon, Ramzan Lakhani, Denis Bégin, and Benoit Latreille developed and implemented exposure assessment methods. A large number of research assistants and interviewers participated, including Marie-Claire Goulet, Jérôme Asselin, and Sally Campbell. We would like to further thank Sally Campbell for editing the manuscript.
The authors declare no conflict of interest.

This study was funded by a number of agencies, including the National Cancer Institute of Canada, the Fonds de recherche du Québec - Santé (FRQ-S), the Canadian Institutes for Health Research (CIHR), and the Guzzo-SRC Chair in Environment and Cancer (JS). AK is a recipient of a CIHR New Investigator award. JL and MCR are recipients of salary awards from the FRQ-S.

\section{References}

1. National Toxicology Program. Final Report on Carcinogens. Background Document for Formaldehyde. Rep Carcinog Backgr Doc. 2010 Jan;(10-5981):i-512.

2. Hauptmann M, Lubin JH, Stewart PA, Hayes RB, Blair A. Mortality from solid cancers among workers in formaldehyde industries. Am J Epidemiol. 2004;159(12):1117-30. http:// dx.doi.org/10.1093/aje/kwh174.

3. IARC (International Agency for Research on Cancer). IARC Monographs on the Evaluation of Carcinogenic Risks to Humans, Vol. 88. Formaldehyde, 2-butoxyethanol and 1-tertbutoxypropan-2-ol. Lyon: IARC; 2006.

4. Overton JH, Kimbell JS, Miller FJ. Dosimetry modeling of inhaled formaldehyde: the human respiratory tract. Toxicol Sci. 2001;64(1):122-34. http://dx.doi.org/10.1093/ toxsci/64.1.122.

5. De Matteis S, Consonni D, Bertazzi PA. Exposure to occupational carcinogens and lung cancer risk. Evolution of epidemiological estimates of attributable fraction. Acta Biomedica. 2008;79 (Suppl 1):34-42.

6. Andjelkovich DA, Janszen DB, Brown MH, Richardson RB, Miller FJ. Mortality of iron foundry workers: 4. Analysis of a subcohort exposed to formaldehyde. J Occup Environ Med. 1995;37(7):826-37. http://dx.doi.org/10.1097/00043764199507000-00012

7. Pinkerton LE, Hein MJ, Stayner LT. Mortality among a cohort of garment workers exposed to formaldehyde: an update. Occup Environ Med. 2004;61(3):193-200. http://dx.doi. org/10.1136/oem.2003.007476.

8. Stroup NE, Blair A, Erikson GE. Brain cancer and other causes of death in anatomists. J Natl Cancer Inst. 1986;77(6):1217-24.

9. Dell L, Teta MJ. Mortality among workers at a plastics manufacturing and research and development facility: 19461988. Am J Ind Med. 1995;28(3):373-84. http://dx.doi. org/10.1002/ajim.4700280307.

10. Coggon D, Harris EC, Poole J, Palmer KT. Extended follow-up of a cohort of British chemical workers exposed to formaldehyde. J Natl Cancer Inst. 2003;95(21):1608-15. http://dx.doi.org/10.1093/jnci/djg046.

11. Stellman SD, Demers PA, Colin D, Boffetta P. Cancer mortality and wood dust exposure among participants in the American Cancer Society Cancer Prevention Study-II (CPS-II). Am J Ind Med. 1998;34(3):229-37. http://dx.doi. org/10.1002/(SICI)1097-0274(199809)34:3<229::AID- 
AJIM4>3.0.CO;2-Q.

12. Hansen J, Olsen JH. Formaldehyde and cancer morbidity among male employees in Denmark. Cancer Causes Control. 1995;6(4):354-60. http://dx.doi.org/10.1007/BF00051411.

13. Hansen J, Olsen JH. Erhvervsmaessig formaldehydudsaettelse og risiko for cancer [Occupational exposure to formaldehyde and risk of cancer]. Ugeskr Laeger. 1996;158(29):4191-4

14. Edling C, Jarvholm B, Andersson L, Axelson O. Mortality and cancer incidence among workers in an abrasive manufacturing industry. Br J Ind Med. 1987;44:57-9.

15. Hayes RB, Blair A, Stewart PA, Herrick RF, Mahar H. Mortality of U.S. embalmers and funeral directors. Am J Ind Med. 1990;18(6):641-52. http://dx.doi.org/10.1002/ ajim.4700180603.

16. Hall A, Harrington JM, Aw TC. Mortality study of British pathologists. Am J Ind Med. 1991;20(1):83-9. http://dx.doi.org/10.1002/ajim.4700200108.

17. Levine RJ, Andjelkovich DA, Shaw LK. The mortality of Ontario undertakers and a review of formaldehyde-related mortality studies. J Occup Med. 1984;26(10):740-6. http:// dx.doi.org/10.1097/00043764-198410000-00014.

18. Bertazzi PA, Pesatori A, Guercilena S, Consonni D, Zocchetti C. Rischio cancerogeno per i produttori di resine esposti a formaldeide: estensione del follow-up. [Carcinogenic risk for resin producers exposed to formaldehyde: extension of followup]. Med Lav. 1989;80(2):111-22.

19. Walrath J, Fraumeni JJF. Mortality patterns among embalmers. Int J Cancer. 1983;31:407-11. http://dx.doi.org/10.1002/ ijc. 2910310403 .

20. Brownson RC, Alavanja MCR, Chang JC. Occupational risk factors for lung cancer among nonsmoking women - a casecontrol study in Missouri (United-States). Cancer Causes Control. 1993;4(5):449-54. http://dx.doi.org/10.1007/ BF00050864.

21. Jensen OM, Andersen SK. Lung cancer risk from formaldehyde. Lancet. 1982;1(8277):913. http://dx.doi.org/10.1016/S01406736(82)92185-7.

22. Andjelkovich DA, Shy CM, Brown MH, Janszen DB, Levine RJ, Richardson RB. Mortality of iron foundry workers. 3. Lung cancer case-control study. J Occup Med. 1994;36(12):1301-9. http://dx.doi.org/10.1097/00043764-199412000-00011.

23. Chiazze L, Watkins DK, Fryar C. Historical cohort mortality study of a continuous filament fiberglass manufacturing plant 1. White men. J Occup Environ Med. 1997;39(5):432-41. http://dx.doi.org/10.1097/00043764-199705000-00009.

24. De Stefani E, Boffetta P, Brennan P, Deneo-Pellegrini H, Ronco A, Gutierrez LP. Occupational exposures and risk of adenocarcinoma of the lung in Uruguay. Cancer Causes Control. 2005;16(7):851-6. http://dx.doi.org/10.1007/ s10552-005-2819-4.

25. Partanen T, Kauppinen T, Hernberg S, Nickels J, Luukkonen R, Hakulinen T, Pukkala E. Formaldehyde exposure and respiratory cancer among woodworkers--an update. Scand J Work Environ Health. 1990;16(6):394-400. http://dx.doi. $\operatorname{org} / 10.5271 /$ sjweh. 1766 .

26. Bond GG, Flores GH, Shellenberger RJ, Cartmill JB, Fishbeck WA, Cook RR. Nested case-control study of lung cancer among chemical workers. Am J Epidemiol. 1986;124(1):53-66.

27. Coggon D, Pannett B, Acheson ED. Use of job-exposure matrix in an occupational analysis of lung and bladder cancers on the basis of death certificates. J Natl Cancer Inst. 1984;72(1):61-5

28. Gérin M, Siemiatycki J, Nadon L, Dewar R, Krewski D. Cancer risks due to occupational exposure to formaldehyde: results of a multi-site case-control study in Montreal. Int J Cancer. 1989;44:53-8. http://dx.doi.org/10.1002/ijc.2910440110.

29. Chiazze L, Watkins DK, Fryar C, Kozono J. A case-control study of malignant and non-malignant respiratory disease among employees of a fibreglass manufacturing facility. 2 . Exposure assessment. Br J Ind Med. 1993;50(8):717-25.

30. Gérin M, Siemiatycki J, Kemper H, Bégin D. Obtaining occupational exposure histories in epidemiologic case-control studies. J Occup Med. 1985;27(6):420-6.

31. Ramanakumar AV, Parent ME, Menzies D, Siemiatycki J. Risk of lung cancer following nonmalignant respiratory conditions: evidence from two case-control studies in Montreal, Canada. Lung Cancer. 2006;53(1):5-12. http://dx.doi.org/10.1016/j. lungcan.2006.04.007.

32. Siemiatycki J. Risk Factors for Cancer in the Workplace. Boca Raton: CRC Press; 1991.

33. Directeur général des élections du Québec. Rapport annuel de gestion 2011-2012 [Annual general report 2011-2012]. Cited 19 December 2012. Available from: www.electionsquebec. qc.ca.

34. Gérin M, Siemiatycki J. The occupational questionnaire in retrospective epidemiologic studies: recent approaches in community-based studies. Applied Occupational \& Environmental Hygiene. 1991;6(6):495-501. http://dx.doi.or g/10.1080/1047322X.1991.10387918.

35. Ramanakumar AV, Parent ME, Richardson L, Siemiatycki J. Exposures in painting-related occupations and risk of lung cancer among men: results from two case-control studies in Montreal. Occup Environ Med. 2011;68(1):44-51. http://dx.doi.org/10.1136/oem.2009.049957.

36. Minister of Manpower and Immigration. Canadian Classification and Dictionary of Occupations 1971. Vol 1. Classification and Definitions. Ottawa: Information Canada; 1974.

37. Breslow NE, Day NE. Statistical Methods in Cancer Research Volume 1 - The analysis of case-control studies. Lyon: International Agency for Research on Cancer; 1980.

38. Leffondré K, Abrahamowicz M, Xiao Y, Siemiatycki J Modelling smoking history using a comprehensive smoking index: application to lung cancer. Stat Med. 2006;25(24):413246. http://dx.doi.org/10.1002/sim.2680.

39. Siemiatycki J, Richardson L, Straif K, Latreille B, Lakhani R, Campbell S, Rousseau MC, Boffetta P. Listing occupational carcinogens; see errata: 113 (2); A 89. Environ Health Perspect. 2004;112(15):1447-59. http://dx.doi.org/10.1289/ ehp.7047. 
40. R Development Core Team. R: A language and environment for statistical computing. . Vienna: R Foundation for Statistical Computing; 2010 [September 2012]; Available from: http:// www.R-project.org/.

41. Chongsuvivatwong V. Epicalc: Epidemiological calculator. R package version 2.10.0.0. 2009 [September 2012]; Available from: http://CRAN.R-project.org/package=epicalc

42. Checkoway H, Ray RM, Lundin JI, Astrakianakis G, Seixas NS, Camp JE, Wernli KJ, Fitzgibbons ED, Li W, Feng Z, Gao DL, Thomas DB. Lung cancer and occupational exposures other than cotton dust and endotoxin among women textile workers in Shanghai, China. Occup Environ Med. 2011;68(6):425-9. http://dx.doi.org/10.1136/oem.2010.059519.

43. Rager JE, Smeester L, Jaspers I, Sexton KG, Fry RC. Epigenetic changes induced by air toxics: formaldehyde exposure alters miRNA expression profiles in human lung cells. Environ Health Perspect. 2011;119(4):494-500. http:// dx.doi.org/10.1289/ehp.1002614.

44. Baumgarten M, Siemiatycki J, Gibbs GW. Validity of work histories obtained by interview for epidemiologic purposes. Am J Epidemiol. 1983;118(4):583-91.
45. Siemiatycki J, Fritschi L, Nadon L, Gerin M. Reliability of an expert rating procedure for retrospective assessment of occupational exposures in community-based case-control studies. Am J Ind Med. 1997;31(3):280-6. http://dx.doi. org/10.1002/(SICI)1097-0274(199703)31:3<280::AIDAJIM3 $>3.0 . C O ; 2-1$.

46. Goldberg MS, Siemiatycki J, Gérin M. Inter-rater agreement in assessing occupational exposure in a case-control study. $\mathrm{Br}$ J Ind Med. 1986;43:667-76.

47. Fritschi L, Nadon L, Benke G, Lakhani R, Latreille B, Parent ME, Siemiatycki J. Validation of expert assessment of occupational exposures. Am J Ind Med. 2003;43(5):519-22. http://dx.doi.org/10.1002/ajim.10208.

48. Hartge P. Participation in population studies. Epidemiology 2006;17(3):252-4. http://dx.doi.org/10.1097/01. ede.0000209441.24307.92.

Received for publication: 23 October 2012 